\title{
PRÁTICA DAS FARMÁCIAS VIVAS DO MUNICÍPIO DE FORTALEZA, CEARÁ, E A NECESSIDADE DE UMA AÇÃO DE EXTENSÃO SISTÊMICA
}

\author{
Leonardo Lopes Rufino ${ }^{1}$ \\ Guillermo Gamarra-Rojas ${ }^{2}$ \\ Mary Anne Medeiros Bandeira ${ }^{3}$ \\ José Ribamar Furtado de Souza ${ }^{4}$ \\ José Newton Pires Reis ${ }^{5}$
}

\section{RESUMO}

A Farmácia Viva (FV) foi idealizada no Ceará e originou a Política Pública em Plantas Medicinais e Medicamentos Fitoterápicos, a qual vem buscando revitalizar essa atividade no Estado. O estudo de multi casos, baseado em análise do conteúdo, objetivou caracterizar as FVs de Fortaleza buscando conhecer a sua dinâmica e os atores sociais e analisá-las quanto à inovação e/ou conformidade com a Política Estadual. As FVs partilham contextos semelhantes, em áreas de pobreza e marginalidade social. Dedicam-se à produção, consumo e distribuição de plantas medicinais, e 30\% também a atender à demanda de fitoterápicos do SUS. Os atores sociais previstos na Política estão pouco evidentes, exceto nas FVs da Universidade Federal do Ceará (UFC) e do Núcleo de Fitoterápicos. Comunitários, acadêmicos e pacientes, substituem aqueles parcialmente e se constituem simultaneamente em produtores, técnicos de transformação e beneficiários. Os hortos são agriculturas urbanas e espaço de aprendizagem e convivência, denotando sua multifuncionalidade. A relativa autonomia na cadeia produtiva implica em prestar atenção à produção integrada e a necessidade de se proporcionar assessoria sistêmica na produção, transformação e gestão. A relação entre normatização e prática sugere considerar as inovações dos sujeitos sociais, que são quem melhor pode retroalimentar a política.

Palavras-chave: extensão rural, fitoterapia, plantas medicinais, políticas públicas.

\footnotetext{
${ }^{1}$ Graduado em Agronomia (UFC). Mestrado em Economia Rural (UFC). Professor da Escola Estadual de Ensino Profissionalizante Francisca Maura Martins, CE. E-mail: leonardorufino@yahoo.com.br

${ }^{2}$ Graduado em Agronomia (UFAL). Mestrado em Ciências Agrárias (EAUFBA). Doutorado em Botânica (UFRPE). Professor do Departamento de Economia Agrícola e do Programa de Pós-Graduação em Economia Rural (UFC). E-mail: ggamarra@terra.com.br

${ }^{3}$ Graduada em Farmácia (UFC). Mestrado em Química (UFC). Doutorado em Química (UFC). Professora do Programa de Pós-Graduação em Ciências Farmacêuticas (UFC). E-mail: mambandeira@yahoo.com.br

${ }^{4}$ Graduado em Agronomia (UFC). Mestrado em Extensão Agrícola (University of Reading). Doutorado em Sociologia do Desenvolvimento e Ciências Políticas (Universidade de Londres). PhD em Economia e Ciências Políticas (London School of Economics and Political Sciences). Professor do Programa de Pós-Graduação em Educação Brasileira (UFC). E-mail: furtado.riba@gmail.com

${ }^{5}$ Graduado em Agronomia (UFC). Doutorado em Economia Aplicada (USP). Professor do Departamento de Economia Agrícola e do Programa de Pós-Graduação em Economia Rural (UFC). E-mail: newton@ufc.br
} 


\title{
LIVING PHARMACIES PRACTICE IN THE MUNICIPALITY OF FORTALEZA, CEARÁ, AND THE NEED FOR A SYSTEMIC EXTENSION ACTION
}

\begin{abstract}
Living Pharmacies (LPs) were conceived in Ceará and originated the Public Policy on Medicinal Plants and Phytotherapy, which has been seeking to revitalize this activity. The multi case study, based on content analysis, aimed to characterize the LPs of Fortaleza seeking to know their dynamics and the social actors and, analyze them in terms of innovation and compliance with policy regulations. LPs share similar contexts in areas of poverty and social marginalization. LPs are dedicated to the production, consumption and distribution of medicinal plants, and $30 \%$ also meet the SUS phytotherapics demand. Social actors established in policy are little evident, except for the Universidade Federal do Ceará and Nufito. Community, academics and patients, override partially and are simultaneously producers, transformation technicians and beneficiaries. Medicinal gardens are urban agriculture and space for learning and acquaintanceship, denoting its multifunctionality. The autonomy in the production chain suggests paying attention to the integrated cultivation of medicinal plants intercropped with vegetables and/or ornamental plants and the need to provide systemic extension services in the production, management and processing. Relationship between regulation and practice suggests to consider the innovations of social actors, for are these who can best provide feedback to policy.
\end{abstract}

Key words: medicinal plants, phytotherapy, public policy, rural extension.

\section{INTRODUÇÃO}

O uso de plantas com fins medicinais remete-se às primeiras civilizações e está presente em diversos grupos humanos, como indígenas e quilombolas. As práticas de cura, geralmente realizadas sob a orientação de pajés e xamãs, vêm associadas a rituais religiosos que garantiram a preservação e disseminação desse conhecimento entre a população brasileira.

A fitoterapia é um tipo de conhecimento relativo às plantas medicinais e constitui uma das práticas integrativas e complementares do Sistema Único de Saúde (SUS) do Brasil. A fitoterapia tem despertado o interesse das indústrias de fármacos nacional e internacional, conforme evidenciado pelo depósito de pedidos de patentes de fitoterápicos no Instituto Nacional de Propriedade Industrial - INPI (FRANÇA; VASCONCELLOS, 2018). Contudo, dos 876 pedidos de patentes analisados entre 1995 e 2017, somente 1,3\% foram concedidas, o que mostra que apesar de o campo tecnológico de fitoterápicos estar entre os de principal interesse por parte dos inventores nacionais, o êxito na concessão ainda é baixo (FRANÇA; VASCONCELLOS, 2018).

Como contraponto a essa indústria de fármacos, têm-se iniciativas em âmbito local de produção e distribuição de plantas medicinais e medicamentos fitoterápicos como o projeto Farmácias Vivas, idealizado há trinta anos pelo professor Francisco José de Abreu Matos no Ceará. Com sua experiência em Farmácias Vivas (FVs), o Ceará coloca em prática a sua própria Política Pública em Plantas Medicinais e Medicamentos Fitoterápicos (PPPMF), por meio do decreto № 30.016 de 30 de dezembro de 2009 que regulamenta a Lei № 12.951, de 07 de outubro de 1999, a qual dispõe sobre a política de implantação da fitoterapia em saúde pública no Ceará (CEARA, 2010). 
A PPPMF inclui diversos atores sociais, tais como técnicos agrícolas, agrônomos, farmacêuticos, médicos, e tem como propósito inserir a agricultura familiar no seu sistema produtivo. Logo, se pergunta: I) como se caracteriza a prática da FV no município de Fortaleza, quando confrontada com a PPPMF? II) existem adaptações e inovações nas FVs guiadas por sujeitos participantes na mesma?

Essas indagações irão permear este trabalho que reconhece o papel social que as políticas públicas têm em melhorar a qualidade de vida da população. No entendimento de Silva (2008) toda política pública é [ou deveria ser] um mecanismo de mudança social, orientada para promover o bem-estar, principalmente dos segmentos mais destituídos, devendo ser um mecanismo de distribuição de renda e de equidade social.

Atualmente a PPPMF passa por um processo de revitalização, buscando qualificar e ampliar a sua atuação no estado do Ceará. Desse modo, tem-se como objetivo deste artigo caracterizar e problematizar o desempenho das FVs no Município de Fortaleza a partir de sua prática. Especificamente o estudo buscou: i) caracterizar a produção, transformação, distribuição e dispensação dos fitoterápicos, buscando conhecer a sua estrutura e dinâmica e os sujeitos envolvidos nessas práticas; ii) realizar análise avaliativa quanto à inovação e/ou conformidade da prática dos sujeitos das FVs com as normas e diretrizes da PPPMF.

O artigo apresenta o contexto em que se desenvolveram a FV e a PPPMF do Ceará e discute conceitos pertinentes ao tema; seguidamente caracteriza a estrutura e dinâmica de seis FVs de Fortaleza na perspectiva dos sujeitos sociais; analisa processos de inovação social e a coerência com a PPPMF e; traz as considerações finais, com sugestões para revitalizar as FVs no Estado.

\section{METODOLOGIA}

A pesquisa constitui um estudo de multi casos de natureza qualitativa e caráter descritivo, explicativo e avaliativo. Foi realizada no período 2014-2015, tendo como unidade de pesquisa as FVs do Município de Fortaleza e, como sujeitos da pesquisa, seis gestores que estão ou estiveram coordenando as FVs e que se mostraram dispostos a interagir com os agentes da investigação. Como instrumento metodológico foi utilizado o questionário semiestruturado.

A análise das informações seguiu etapas da análise do conteúdo, adaptadas de Bardin (2002). Inicialmente, buscando-se caracterizar as FVs as respostas foram agrupadas por semelhança de conteúdo em função das seguintes categorias de agrupamento e análise: origem e contexto; motivações; sujeitos; formas organizativas; práticas produtivas; práticas terapêuticas; finalidades. Para realização da análise avaliativa quanto à inovação e/ou conformidade da prática dos sujeitos das FVs com as normas e diretrizes da PPPMF, informações selecionadas a partir da caracterização das FVs foram organizadas em quadro síntese, contendo: contexto inicial, sujeitos diretos e indiretos e efeitos diretos e indiretos. O conjunto de informações e análises foi enriquecido e confrontado com informação documental e bibliográfica, caracterizando uma triangulação de dados e informação primários e secundários, como forma de assegurar a validade interna em pesquisa qualitativa.

\section{CONTEXTO E CONCEITOS RELEVANTES}

O estudo das políticas públicas surgiu na Europa como um desdobramento dos trabalhos baseados em teorias explicativas sobre o papel do Estado e de uma de suas mais importantes instituições que é o governo produtor de políticas públicas. Nos Estados Unidos a área de políticas públicas surge no cenário acadêmico sem 
estabelecer relações com as bases teóricas sobre o papel do Estado, passando a dar ênfase à ação dos governos (SOUSA, 2006).

Assim, do ponto de vista teórico-conceitual, a política pública em geral e a política social em particular são campos multidisciplinares, e seu foco está nas explicações sobre a natureza da política pública e seus processos. Elas repercutem na economia e nas sociedades, daí porque qualquer teoria relacionada à política pública precisa também explicar as inter-relações entre Estado, política, economia e sociologia (SOUSA, 2006).

Define-se o Estado como o conjunto de instituições permanentes, tais como órgãos legislativos, tribunais, Empresas de Assistência Técnica e Extensão Rural (ATER) e outras que não formam o governo, mas que possibilitam sua ação. $O$ governo é o conjunto de programas e projetos que partem da sociedade para a sociedade como um todo. Essa perspectiva das políticas públicas vai além do aspecto de políticas governamentais, considerando que o governo não é a única instituição a promover políticas públicas. Organizações não governamentais (ONGs), empresas concessionárias e associações diversas da sociedade também podem ser incluídas como agentes de políticas públicas. O setor empresarial com fins lucrativos não é considerado um agente fornecedor de políticas públicas (HEIDEMANN; SALM, 2008), mas pode influenciar nelas.

As políticas públicas, também chamadas de políticas sociais, se referem a ações que determinam o padrão de proteção social adotado pelo Estado, voltadas, em princípio, para a redistribuição dos benefícios sociais visando à diminuição das desigualdades estruturais produzidas pelo desenvolvimento econômico. As políticas sociais têm suas raízes nos movimentos populares do século XIX, relacionados aos conflitos surgidos entre capital e trabalho, no decorrer das primeiras revoluções industriais (HÖFLING, 2001; FLEURY; OUVERNEY, 2008).

A proteção social se institucionalizou pelo desenvolvimento de amplos sistemas de provisão de bens e serviços de saúde, educação e assistência, visando a ampliar o bem-estar da população. Surgia desse modo o estado de bem-estar social (FLEURY; OUVERNEY, 2008).

No Brasil do século XVIII a assistência médica era pautada na filantropia e na prática liberal. No século XIX, em decorrência das transformações econômicas e políticas, algumas iniciativas surgiram no campo da saúde pública. A intervenção estatal nesse setor só vai ocorrer no século $X X$, mais efetivamente na década de trinta (BRAVO, 2008).

Simultaneamente, as plantas medicinais, que sempre fizeram parte do acervo cultural e das práticas de prevenção e de tratamento de doenças dos povos indígenas e tradicionais, foram integradas ao saber popular, entendido como aquele que é passado de geração em geração através da educação não formal ou baseado em imitação ou experiência pessoal, e têm se tornado objeto de estudo por universidades e empresas de fármacos e, assim, uma fonte de produtos naturais biologicamente ativos.

Dos pesquisadores na área destacaram-se os professores da Universidade Federal do Ceará (UFC) Francisco José de Abreu Matos, farmacologista, e Afrânio Fernandes, botânico, os quais percorreram o Nordeste, identificando e catalogando espécies de plantas de uso medicinal pela população local. Bandeira (2009) relata que "Exequível para o professor Matos era buscar nas plantas já consagradas pela cultura popular o remédio, no plano da atenção básica, que pudesse tratar um vasto elenco de doenças que acomete a população brasileira". Tal concepção valoriza o conhecimento popular, agregando-lhe valor científico com orientações de uso e indicação terapêutica. 
Seus estudos resultaram na criação da FV, que pode ser compreendida como um horto onde se cultiva plantas medicinais, podendo ser realizado posterior beneficiamento e preparo de algum medicamento, como o fitoterápico, a ser utilizado por pessoas que desejam realizar tratamento à base de remédios naturais e de baixo custo. Sua produção vem sendo subsidiada por órgãos públicos e distribuída gratuitamente pelo SUS nas Unidades de Saúde.

Em 1997 as FVs foram institucionalizadas pela Secretaria da Saúde do Estado do Ceará (SESA), por meio do Programa Estadual de Fitoterapia e, no mesmo ano, foi criado o Núcleo de Fitoterápicos da Coordenadoria de Assistência Farmacêutica (NUFITO/COASF). Em 2008 o Comitê Estadual de Fitoterapia, por meio do NUFITO, regulamenta a Lei da Fitoterapia no Estado do Ceará (RUFINO, 2015). Em decorrência da PPPMF, foi estabelecida uma tipologia para as FVs desse estado (CEARÁ, 2010), conforme segue:

\begin{abstract}
Farmácia Viva I - Nesta é desenvolvido o cultivo de plantas medicinais, a partir de hortas em unidades de FVs comunitárias e/ou unidades do SUS, tornando acessível à população assistida a planta medicinal in natura e a orientação sobre a correta preparação e uso dos remédios caseiros.

Farmácia Viva II - Nesta são realizadas a produção e dispensação de plantas medicinais secas. Para tanto, deve possuir uma adequada estrutura de processamento da matériaprima, para tornar acessível à população a planta medicinal seca. Poderá ainda desenvolver as atividades previstas no tipo I.

Farmácia Viva III - Se destina à preparação de fitoterápicos padronizados, preparados em áreas específicas para as operações farmacêuticas, de acordo com as Boas Práticas de Preparação de Fitoterápicos (BPPF), visando ao provimento das unidades do SUS. A FV III poderá realizar as atividades previstas para os tipos I e II.
\end{abstract}

Em 2009, por meio do Decreto № 30.016, de 30 de dezembro de 2009, o Ceará passa a estabelecer as instâncias ou secretarias responsáveis pelo estímulo à PPPMF, cabendo à SESA a política de incentivo à pesquisa, com ênfase na biodiversidade regional, e o estímulo às iniciativas comunitárias e da agricultura familiar, juntamente com a Secretaria do Desenvolvimento Agrário - SDA (CEARÁ, 2010).

Desse modo, amplia-se a participação de atores governamentais e da sociedade civil na PPPMF ao considerar as iniciativas comunitárias e a agricultura familiar (RUFINO, 2015) e se faz evidente a estreita relação entre o resgate de conhecimento (plantas medicinais), a produção de novo conhecimento (fitoterápicos) e a ação do Estado como promotor da atividade produtiva e distributiva (política pública).

Torna-se aparente um enfoque centrado no produto (planta medicinal e fitoterápico), denotando uma abordagem técnica e setorial, que valoriza poucas variáveis, a qual se tem generalizado nas ciências agrárias (GAMARRA-ROJAS; SILVA; VIDAL, 2017), como resultado do método analítico historicamente construído pela ciência, onde a busca de apreensão da realidade se dá de forma fragmentada, iniciando pela separação das ciências sociais das naturais e subsequentemente a sua separação em disciplinas (GUZMÁN; OTTMANN, 1999; 2000) e, no âmbito da produção, em produtos. 
Verifica-se também um desenho linear e unidirecional de difusão de tecnologia, próximo do modo de difusão de inovações de Rogers (1983), institucionalizado e dominante no ensino e na pesquisa brasileira, conforme destacava Fonseca (1985) faz mais de trinta anos, onde o conhecimento flui de um agente emissor, mediado por um agente intermediário, para um agente receptor. Para Fonseca (1985) o modelo difusionista inovador parte do princípio de que as mudanças nas sociedades rurais se dão por intervenções técnicas e não por alterações nas estruturas sociopolíticas e econômicas dessas sociedades.

Nessa perspectiva, no contexto da normatividade da PPPMF, cabe à SESA estimular a produção de tecnologia nas instituições de ensino e pesquisa e à SDA, que congrega diversas organizações do estado como a Empresa de Assistência Técnica e Extensão Rural (EMATERCE), o papel de mediador, que neste contexto seria o de agente que intervém na facilitação de capacitações e orientação técnica na produção e transformação das plantas medicinais junto a comunitários ou agricultores familiares, para que a FV se torne uma realidade social.

\section{CARACTERIZAÇÃO DAS FARMÁCIAS VIVAS DE FORTALEZA}

A década de 80 do século passado constituiu um período de ativa criação de Farmácias Vivas no município de Fortaleza, com trinta FVs. Contudo, a partir de 2008 , ano do falecimento do Prof. Mattos, o número dessas unidades se reduziu a cerca de cinco (TEÓFILO, 2015). O quadro 1 apresenta FVs ativas e inativas em 2015 cujos gestores se dispuseram a dialogar com os agentes da presente pesquisa.

Quadro 1 - Relação das Farmácias Vivas estudadas em Fortaleza, CE, 2015.

\begin{tabular}{|l|c|c|}
\hline \multicolumn{2}{|c|}{ Farmácia Viva } & \multicolumn{2}{c|}{ Status } \\
\cline { 2 - 3 } & Ativa & Inativa \\
\hline Centro de Atenção Psicossocial & $\mathrm{x}$ & \\
\hline Escola Profissionalizante Marvin & & $\mathrm{X}$ \\
\hline Movimento Mulheres da Itaoca & $\mathrm{X}$ & \\
\hline Fundo de Apoio Comunitário & $\mathrm{x}$ & \\
\hline Quatro Varas & $\mathrm{X}$ & \\
\hline Universidade de Fortaleza & $\mathrm{x}$ & \\
\hline \multicolumn{1}{|c|}{ Total } & 5 & 1 \\
\hline
\end{tabular}

Fonte: Resultados da pesquisa.

$\mathrm{Na}$ figura 1 são apresentados os fluxogramas de produção, processamento e consumo das FVs estudadas. As mesmas foram classificadas segundo tipologia da SESA do estado do Ceará (CEARÁ, 2010) apresentada anteriormente, na terceira seção deste artigo. 
Figura 1- Fluxogramas de produção, processamento e consumo das Farmácias Vivas.

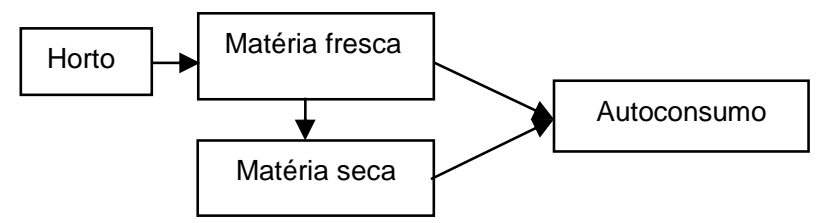

A. Farmácia Viva Tipo I: Centro de Apoio

Psicossocial

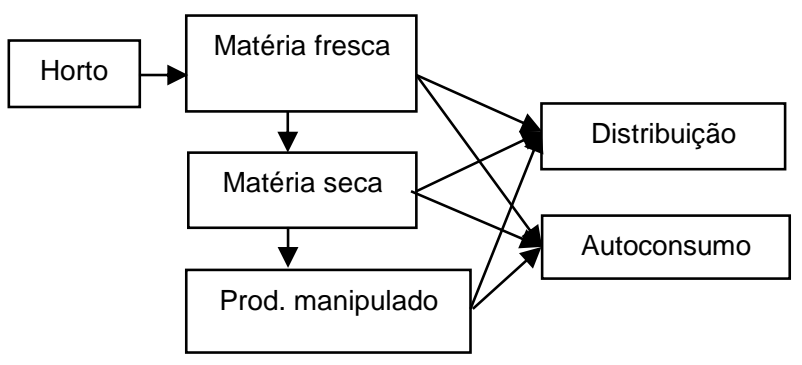

B. Farmácias Vivas

Tipo II: Escola Marvin e

Fundo de Apoio

Comunitário

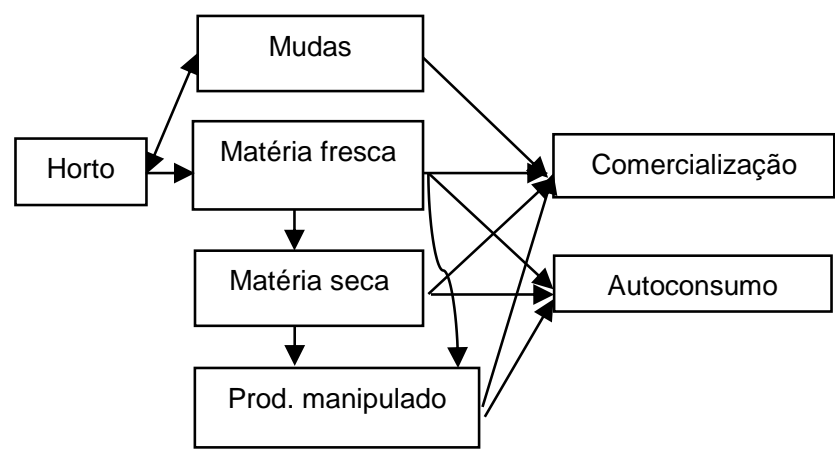

C. Farmácia Viva Tipo

II: Movimento

Mulheres da Itaoca

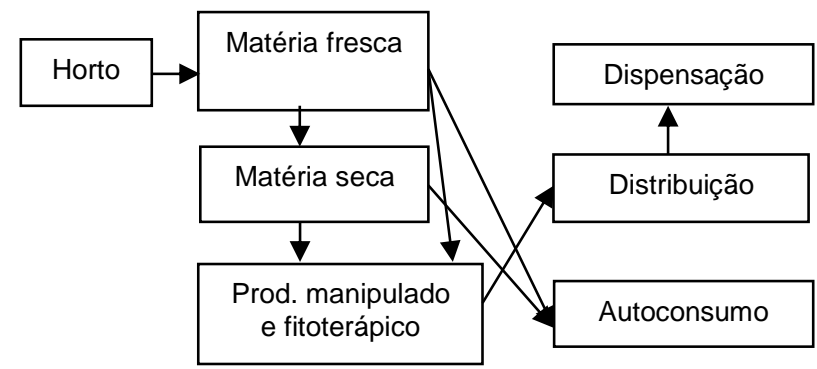

D. Farmácias Vivas

Tipo III: Quatro Varas e UNIFOR

Fonte: Resultados da pesquisa. 


\subsection{FARMÁCIA VIVA DO CENTRO DE ATENÇÃO PSICOSSOCIAL (CAPS)}

Criada na primeira década de 2000 e localizada no Bairro Itaperi, apresenta um horto de plantas medicinais para consumo interno e se constitui em espaço de convivência e formação terapêutica dos pacientes, onde são realizadas atividades de conscientização das propriedades terapêuticas das plantas medicinais (Figura 1A).

Estão envolvidos na produção de plantas medicinais um enfermeiro e um agente social do CAPS, juntamente com os pacientes da unidade de saúde. As mesmas são consumidas frescas ou secas. A dispensação dessa produção é realizada no próprio local por profissionais da saúde, sendo entregue aos pacientes como complemento da medicação controlada. Esses profissionais também realizam oficinas, orientando os pacientes sobre usos e funções das plantas medicinais.

Os sujeitos da FV do CAPS dialogam com a categoria de atores governamentais, conforme definidas por Secchi (2013), no sentido que não estão muito evidentes no debate de políticas públicas e são os executores da mesma, podendo ser chamados de atores burocratas. Contudo, diverge de Secchi (2013) pelo fato dos atores sociais do CAPS não serem concursados, mas manterem contratos por tempo determinado, caracterizando a precarização do trabalho que vem se generalizando no Brasil.

Quando considerados os atores sociais previstos na PPPMF, verifica-se a ausência de agrônomo e de técnico agrícola. Devido às atividades serem de produção e fornecimento de plantas medicinais e de orientação sobre a preparação e uso das mesmas a FV do CAPS se relaciona ao Tipo I.

\subsection{FARMÁCIA VIVA DA ESCOLA PROFISSIONALIZANTE MARVIN}

Foi um espaço de produção de plantas medicinais, convivência dos estudantes e de visitação de grupos de idosos. Os sujeitos envolvidos foram professores dessa escola, os quais participaram de capacitações na UFC. A escola proporcionou os recursos para a construção dos canteiros e aquisição do sistema de irrigação.

O cultivo e colheita realizados no horto ficavam a cargo de professores e estudantes (Figura 1B). O horto proporcionava a matéria prima, que podia ser utilizada fresca ou seca. As plantas eram usadas na forma de chás pelos professores e estudantes. A parte da produção destinada ao processamento passava por secagem, moagem e fracionamento em forma de sachês e ficava a cargo dos professores. A distribuição dos sachês era realizada durante reuniões com os pais ou entregue diretamente aos estudantes participantes das práticas de cultivo, chegando assim à família do estudante. Por se tratar de plantas medicinais de consumo livre, não se realizava prescrição médica.

A FV Marvin esteve ativa por dois anos e em 2012 seu funcionamento foi interrompido por escassez de água. Era composta por atores governamentais oriundos do quadro de professores da Escola, os chamados burocratas no entendimento de Secchi (2013). Entretanto, esses profissionais não se ajustam ao conceito de burocratas executores da política pública, pois eles mesmos idealizaram a FV, conseguindo o apoio da administração escolar, que abriu o seu orçamento em prol da proposta. Também articularam parceria com a prefeitura de Fortaleza e com a UFC. Os estudantes da escola atuaram como colaboradores. Acompanhando Silva (2008), os estudantes são um grupo de interesse pelo fato de serem os potenciais beneficiários desse programa social, podendo ser eles os responsáveis pela transformação dos problemas em questões sociais que integrarão ou não as agendas públicas. 
Quanto aos atores sociais previstos na legislação, como agrônomos e farmacêuticos, a FV da Escola Marvin não apresentava nenhum destes. Perante a política estadual pode ser relacionada à FV II.

\subsection{FARMÁCIA VIVA DO MOVIMENTO MULHERES DA ITAOCA}

Localizada no bairro da Parangaba, é um espaço aberto à visitação de estudantes e idosos. Foi pensada por um grupo de mulheres com apoio do Instituto Juazeiro, buscando soluções para problemas do bairro relacionados à violência, drogas, álcool e falta de oportunidades, que afligem principalmente às mulheres. Em 2006 iniciaram as atividades através do Centro de Referência em Agricultura Urbana Sustentável, contando com o apoio da Secretaria de Desenvolvimento Econômico, da UFC e da Prefeitura de Fortaleza, em cujo terreno se desenvolve a FV (BARROS; GAMARRA-ROJAS; SOUSA, 2017).

Conta com um horto, um espaço para produção de mudas e instalações rústicas para secagem e manipulação das plantas. Os produtos são comercializados e/ou consumidos pelos membros da FV e seus familiares (Figura 1C).

A FV é composta por seis pessoas da comunidade, na faixa de 50 a 75 anos, em sua maioria oriunda do campo, o que lhes proporcionou base para as atividades de produção no horto (BARROS; GAMARRA-ROJAS; SOUSA, 2017). Participam de todas as etapas do processo, partindo da produção de plantas e mudas, passando pela secagem e elaboração dos remédios caseiros, até a comercialização e gestão.

No horto se cultiva elevada biodiversidade, composta por cerca de trinta espécies, entre frutíferas, hortaliças, ornamentais e medicinais. Em pequena área se produz mudas, tanto para renovação do horto quanto para comercialização. Segundo Barros, Gamarra-Rojas e Sousa (2017), a idade avançada limita a capacidade de trabalho das mulheres nas tarefas mais pesadas, o que é superado por meio de mutirões com apoio de voluntários.

No processamento apresenta estrutura para secagem das plantas e elaboração de cerca de vinte remédios caseiros, tais como: lambedores, garrafadas, sabonete líquido e sal culinário (BARROS; GAMARRA-ROJAS; SOUSA, 2017). A comercialização é realizada na FV, nas casas dos membros do grupo e na Feira Agroecológica do bairro do Benfica.

As ervas cultivadas são oriundas do Horto Matriz da UFC, onde as plantas matrizes passaram por processo de validação quanto à sua efetividade medicinal e recebem acompanhamento de profissionais da botânica sistemática, farmacologia e agronomia. A UFC também contribuiu capacitando os membros comunitários para a manipulação de produtos, bem como através do Grupo Agroecológico, composto por estudantes de graduação das Ciências Agrárias, que colabora nos mutirões, na orientação técnica e difusão dessa iniciativa em diversos espaços.

O Movimento Mulheres da Itaoca, na acepção de Secchi (2013), é um ator coletivo não governamental que age intencionalmente em busca de melhorias individuais e coletivas por meio da diversificação de sua dieta com hortaliças e frutas e acesso a remédio de elevado valor biológico e de baixo custo e, principalmente, gerando ocupação, alguma renda e propiciando a sua socialização.

Ao se considerar a normatização da política, a FV da Itaoca não conta com agrônomo nem técnico agrícola. Os profissionais da saúde obviamente não estão presentes, pois não se produz fitoterápico. A FV pode ser classificada no Tipo II. Contudo, o fluxograma apresenta variações na FV Tipo II do Movimento Mulheres da Itaoca, onde a produção e comercialização de mudas e a comercialização de produtos manipulados constituem inovações ao padrão. Ressalta-se que a comercialização 
direta de produtos é condizente com o objetivo da PPPMF de gerar renda aos produtores.

\subsection{FARMÁCIA VIVA DO FUNDO DE APOIO COMUNITÁRIO (FAC)}

Os objetivos e funções dessa FV estão integrados aos do FAC, que é uma organização de educação, sem fins lucrativos, localizada no bairro Jangurussu. A inauguração dessa FV em 2009 teve especial importância para esse bairro, pois durante 20 anos o mesmo foi sede do aterro sanitário de Fortaleza e teve sua imagem associada ao lixo e à poluição ambiental (MAURO, 2009).

Nesse contexto, a FV é um espaço de convivência, aberto à visitação pela comunidade, e de formação pedagógica, onde os estudantes da educação básica do FAC realizam atividades de conscientização ambiental e aprendem sobre as funções das plantas medicinais. Também são realizadas oficinas de elaboração de óleos para massagens e tinturas por pessoas externas à FV. Apresenta um horto de plantas medicinais e instalações para transformação em produtos manipulados (Figura 1B).

Inicialmente a UFC capacitou os professores e estudantes da FAC. As práticas de jardinagem e cultivo são realizadas por um voluntário do bairro. O processamento e transformação estão sob a responsabilidade de duas professoras. A distribuição dessa produção é feita no próprio local, não visando benefício econômico. Os produtos são consumidos internamente na forma de chás ou entregues aos visitantes e às pessoas que participam das oficinas.

Sendo uma organização sem fins lucrativos, seguindo a classificação de Secchi (2013), trata-se de atores do terceiro setor. Não apresenta os atores sociais previstos na PPPMF, estes aparecendo eventualmente como membros externos à instituição. Pelas suas características essa FV está relacionada ao Tipo II.

\subsection{FARMÁCIA VIVA DAS QUATRO VARAS}

Essa FV constitui um ambiente de produção de plantas medicinais com características de jardim, o qual possui um laboratório rústico para elaboração de fitoterápicos. Seu funcionamento acompanha os objetivos e atividades da ONG Quatro Varas.

O projeto Quatro Varas, uma iniciativa da ONG, foi criado em 1987, no Bairro do Pirambu, uma das maiores favelas de Fortaleza, pelo psiquiatra e antropólogo Adalberto Barreto, da UFC. Hoje é reconhecido internacionalmente como um exemplo exitoso de Terapia Comunitária Integrativa (TCl), que alia o saber científico e o conhecimento popular às vivências interpessoais, contribuindo na (re)construção da identidade individual e coletiva (RÊGO, 2014).

A prática da TCl surgiu em 1986 no Pirambu, como resposta a uma crescente demanda de indivíduos com sofrimento psicossocial que buscavam auxílio jurídico junto ao Projeto de Apoio aos Direitos Humanos da favela (JATAI; SILVA, 2012). Em 2008 a TCl, de modo semelhante à $\mathrm{FV}$, passou a fazer parte das práticas complementares de saúde (NEDER; PINHEIRO, 2010).

O horto é utilizado como espaço de convivência dos beneficiários e funcionários da ONG e é aberto à visitação. As ervas cultivadas são oriundas do Horto Matriz da UFC, a qual Ihes proporcionou capacitação em produção de plantas medicinais e medicamentos fitoterápicos.

A produção é realizada por um jardineiro. O horto proporciona a matéria prima que pode ser utilizada fresca, seca e/ou pode ser transformada de diversas maneiras, como xarope, tintura e elixir (Figura 1D). 
Quando utilizadas in natura na ONG, as mesmas são direcionadas aos sujeitos que participam da $\mathrm{TCl}$. As práticas de secagem, moagem e transformação em produtos processados, são realizadas por técnicas de manipulação. Uma farmacêutica e uma acadêmica de Farmácia do bairro fazem a orientação sobre o uso voluntariamente. Os fitoterápicos em sua maioria são destinados à Regional I de Saúde, para serem distribuídos às Unidades de Saúde, onde médicos e enfermeiros fazem a prescrição dos medicamentos à população.

Os membros dessa FV constituem atores do terceiro setor, conforme Heidemann e Salm (2008). Os atores governamentais, tidos por Secchi (2013) como burocratas, são os médicos e enfermeiros da Regional I que realizam a prescrição dos fitoterápicos na unidade de saúde. A maioria dos sujeitos dessa FV está contemplada nas normas da PPPMF, com exceção do agrônomo e do técnico agrícola. Essa FV é do Tipo III.

\subsection{FARMÁCIA VIVA DA UNIVERSIDADE DE FORTALEZA (UNIFOR)}

Localizada no bairro Edson Queiroz, essa FV iniciou suas atividades em 2009, em parceria com a prefeitura de Fortaleza e o Lar Torres de Melo, uma ONG de saúde e proteção social. Tem por objetivo atender à demanda de fitoterápicos do SUS e, por se tratar de uma instituição educacional, apresenta também a função de ensinoaprendizagem e extensão. Conta com um horto para a produção de plantas medicinais, um espaço para beneficiamento das plantas e uma área de produção de fitoterápicos (Figura 1D).

O cultivo está sob responsabilidade de um agrônomo cedido pela prefeitura. Um técnico agrícola, também cedido pela prefeitura, realiza a secagem, moagem e extração do óleo essencial. A produção de fitoterápicos é realizada por um farmacêutico do Lar Torres de Melo. No processamento e na produção de fitoterápicos existe participação ativa de estudantes de Farmácia dessa universidade (TEÓFILO, 2015). O enfermeiro do Lar Torres de Melo distribui os fitoterápicos para o Núcleo de Atenção Médica Integrada da Universidade e a três postos da Secretaria Executiva Regional VI (TEÓFILO, 2015). Tem como responsável pela dispensação dos medicamentos fitoterápicos o farmacêutico e o enfermeiro.

O agrônomo, juntamente com os profissionais de saúde, orienta sobre o uso das plantas e fitoterápicos a estudantes da universidade, outros profissionais de saúde, escolas e demais público externo, por meio de oficinas de produção e transformação. Estes podem ser qualificados, segundo as categorias de Secchi (2013), como beneficiários indiretos dessa política. Essa FV é do Tipo III.

\section{SUJEITOS, INOVAÇÃO E IMPLICAÇÕES PARA A POLÍTICA PÚBLICA}

As FVs pesquisadas estão contempladas nos tipos estabelecidos pela PPPMF, com pequenas variações (Quadro 2): uma no tipo I (CAPS), três no tipo II (Escola Marvin, Mulheres da Itaoca e FAC) e duas no tipo III (Quatro Varas e UNIFOR). 
Quadro 2 - Contexto, efeitos e sujeitos das Farmácias Vivas de Fortaleza, CE, 2015.

\begin{tabular}{|c|c|c|c|}
\hline Tipo & Contexto & Efeitos & Sujeitos \\
\hline \multicolumn{4}{|c|}{ Centro de Atenção Psicossocial (CAPS) } \\
\hline I & $\begin{array}{l}\text { Bairro carente; } \\
\text { Organização } \\
\text { de apoio } \\
\text { comunitário. }\end{array}$ & $\begin{array}{l}\text { Diretos: Consumo de plantas } \\
\text { medicinais complementar ao serviço } \\
\text { médico-terapêutico. } \\
\text { Indiretos: Espaço de convivência e } \\
\text { conscientização sobre propriedades } \\
\text { terapêuticas. }\end{array}$ & $\begin{array}{l}\text { Produção por enfermeiro, } \\
\text { agente social e pacientes; } \\
\text { Orientação de uso por } \\
\text { profissional de saúde; } \\
\text { Gestão por enfermeiro. }\end{array}$ \\
\hline \multicolumn{4}{|c|}{ Escola Profissionalizante Marvin } \\
\hline II & $\begin{array}{l}\text { Professores } \\
\text { interessados } \\
\text { em ensino- } \\
\text { aprendizagem } \\
\text { social e } \\
\text { produtiva. }\end{array}$ & $\begin{array}{l}\text { Diretos: Consumo de plantas } \\
\text { medicinais por acadêmicos; } \\
\text { Distribuição gratuita a familiares e } \\
\text { visitantes. } \\
\text { Indiretos: Espaço de convivência e } \\
\text { visitação; Aprendizagem social e } \\
\text { produtiva de estudantes. }\end{array}$ & $\begin{array}{l}\text { UFC ou Nufito na } \\
\text { capacitação; Produção } \\
\text { por professores e } \\
\text { estudantes; } \\
\text { Processamento e gestão } \\
\text { por professor. }\end{array}$ \\
\hline \multicolumn{4}{|c|}{ Movimento Mulheres da Itaoca } \\
\hline II & $\begin{array}{l}\text { Bairro carente; } \\
\text { Organização } \\
\text { de apoio } \\
\text { comunitário; } \\
\text { Grupo de } \\
\text { interesse. }\end{array}$ & $\begin{array}{l}\text { Diretos: Consumo de plantas } \\
\text { medicinais, produtos manipulados, } \\
\text { hortaliças e frutas; Ocupação e } \\
\text { renda; Comercialização a baixo } \\
\text { custo. } \\
\text { Indiretos: Visitação e esclarecimento } \\
\text { à população; Aprendizagem social e } \\
\text { produtiva de estudantes; Interação } \\
\text { institucional. }\end{array}$ & $\begin{array}{l}\text { UFC ou Nufito na } \\
\text { capacitação; Produção e } \\
\text { elaboração de produtos } \\
\text { manipulados por grupo de } \\
\text { interesse; Gestão por } \\
\text { liderança comunitária; } \\
\text { Voluntariado de } \\
\text { estudantes na produção. }\end{array}$ \\
\hline \multicolumn{4}{|c|}{ Fundo de Apoio Comunitário (FAC) } \\
\hline II & $\begin{array}{l}\text { Bairro carente } \\
\text { e sujeito à } \\
\text { poluição; } \\
\text { Organização } \\
\text { social de } \\
\text { educação } \\
\text { infantil e } \\
\text { pesquisa. }\end{array}$ & $\begin{array}{l}\text { Diretos: Consumo de plantas } \\
\text { medicinais e produtos manipulados; } \\
\text { Distribuição gratuita a público } \\
\text { externo. } \\
\text { Indiretos: Visitação, oficinas e } \\
\text { esclarecimento à população; } \\
\text { Aprendizagem social e produtiva de } \\
\text { estudantes. }\end{array}$ & $\begin{array}{l}\text { UFC ou Nufito na } \\
\text { capacitação; Produção } \\
\text { por voluntário; Elaboração } \\
\text { de produtos manipulados } \\
\text { e gestão por professor. }\end{array}$ \\
\hline \multicolumn{4}{|c|}{ Quatro Varas } \\
\hline III & $\begin{array}{l}\text { Bairro carente; } \\
\text { Problemas } \\
\text { psicossociais; } \\
\text { Projeto de } \\
\text { direitos } \\
\text { humanos. }\end{array}$ & $\begin{array}{l}\text { Diretos: Autoconsumo de plantas } \\
\text { medicinais por sujeitos da TCl; } \\
\text { Atenção à demanda de fitoterápicos } \\
\text { do SUS; Distribuição de produtos a } \\
\text { visitantes e participantes de oficinas. } \\
\text { Indiretos: Espaço de convivência e } \\
\text { visitação de público externo; } \\
\text { Aprendizagem social. }\end{array}$ & $\begin{array}{l}\text { UFC ou Nufito na } \\
\text { capacitação; Produção } \\
\text { por jardineiro; Elaboração } \\
\text { do fitoterápico por } \\
\text { farmacêutica; Prescrição } \\
\text { por profissionais de } \\
\text { saúde; Gestão por } \\
\text { administrador. }\end{array}$ \\
\hline \multicolumn{4}{|c|}{ Universidade de Fortaleza (UNIFOR) } \\
\hline III & $\begin{array}{l}\text { Curso de } \\
\text { Farmácia; } \\
\text { ONG de } \\
\text { saúde e } \\
\text { proteção } \\
\text { social. }\end{array}$ & $\begin{array}{l}\text { Diretos: Atenção à demanda de } \\
\text { fitoterápicos do SUS; Ensino, } \\
\text { pesquisa e extensão. } \\
\text { Indiretos: Oficinas e esclarecimento } \\
\text { à população; Interação institucional. }\end{array}$ & $\begin{array}{l}\text { UFC ou Nufito na } \\
\text { capacitação; Produção } \\
\text { por agrônomo; } \\
\text { Processamento por } \\
\text { técnico agrícola; } \\
\text { Elaboração e prescrição } \\
\text { do fitoterápico por } \\
\text { profissionais de saúde; } \\
\text { Gestão por farmacêutica. }\end{array}$ \\
\hline
\end{tabular}

Fonte: Resultados da pesquisa. 
Essas FVs partilham contextos semelhantes, caracterizados por estarem localizadas em bairros carentes com problemas associados à pobreza e marginalidade social; preexistência de organizações de cunho social e grupos de interesse locais. As FVs da UNIFOR, do FAC e da Escola Marvin partilham a missão institucional do ensino-aprendizagem.

Observando os efeitos diretos, compreendidos como uma aproximação aos resultados alcançados pelas FVs, destacam-se a produção e consumo de plantas medicinais pelos sujeitos das FVs e seus beneficiários, sejam estes voluntários, estudantes, pacientes etc. Segue a distribuição gratuita e comercialização dos produtos a baixo custo aos familiares e comunidade. O objetivo de ensinoaprendizagem está sendo alcançado nas instituições de ensino. Somente nas Quatro Varas e na UNIFOR existe a intenção de atender diretamente à demanda de fitoterápicos de Unidades de Saúde do Ceará. Desse modo, a maior parte das FVs tem centrado suas ações na produção, autoconsumo e distribuição de plantas medicinais.

Nos efeitos indiretos cabe destaque aos hortos como espaços de convivência; a oferta de oficinas e orientações sobre os usos e funções das plantas medicinais e dos fitoterápicos e; a aprendizagem social e institucional dos sujeitos, ao estabelecerem parcerias diversas. Então, o contexto e a missão da organização constituem a base da motivação dos sujeitos e dos objetivos dessas FVs. Nesse ambiente a política pública têm estimulado processos sociais e gerado frutos diversos, ancorados em ação coletiva e solidariedade.

Nas normas da PPPMF do Ceará, Decreto № 30.016 de 30 de dezembro de 2009, cabe à SESA estimular a produção de tecnologia nas instituições de ensino e pesquisa e à SDA, por meio da EMATERCE, o papel de agente facilitador de capacitações e orientação técnica na produção e transformação das plantas medicinais. O Projeto Farmácias Vivas da UFC e o NUFITO têm conquistado credibilidade através da 'garantia' genética do material de propagação vegetal dos seus hortos matriz e pela qualidade da informação e capacitação proporcionada, referente às propriedades medicinais, produção, processamento e transformação. Assim, dentre os atores governamentais, a UFC e o NUFITO vêm promovendo o uso de plantas medicinais e a fitoterapia na saúde pública. Já a SDA, que deveria estimular as iniciativas comunitárias e da agricultura familiar, ainda não se faz presente. Provavelmente devido a que os serviços de ATER somente atentaram para o tema das plantas medicinais e dos fitoterápicos nos últimos anos. Mas, também devido à insuficiência de técnicos e descontinuidade da ação dos agentes de ATER no Ceará, como resquício indesejável do desmonte generalizado das ATER, no começo da década de 90 quando o Governo Federal aboliu a Embrater, órgão de representação nacional da ATER, e diminuiu a contribuição financeira ao sistema de assessoria técnica pública (GAMARRA-ROJAS; SILVA; VIDAL, 2017).

A prática das FVs de Fortaleza sugere uma dinâmica desenvolvida localmente. Os sujeitos prescritos na política para a produção das plantas medicinais, tais como agrônomo e técnico não aparecem, exceto na UNIFOR. Desse modo, outros atores sociais assumem essa atividade, tais como professores, líderes comunitários e pacientes clínicos, os quais são produtores e beneficiários ao mesmo tempo. No processamento e transformação o concurso dos sujeitos prescritos na política é maior. Nas Quatro Varas e na UNIFOR, cujo propósito é atender à demanda de fitoterápicos do SUS, estão presentes o farmacêutico e o técnico em manipulação e a dispensação é realizada por profissionais de saúde. Nas outras FVs diferentes sujeitos estão incluídos, tendo participação de professores, estudantes e comunitários, que são ao mesmo tempo 'técnicos' de transformação e beneficiários. 
Os sujeitos das FVs muitas vezes têm suas raízes no campo, o que os estimulou e lhes proporcionou competências para a agricultura urbana, como as Mulheres da Itaoca, que produzem plantas medicinais, hortaliças e frutas para autoconsumo e renda. Há outras motivações vinculadas à prática agrícola, pois esta pressupõe o trato com a terra e as plantas, desse modo propiciando espaço didáticopedagógico para re-conexão com a natureza. Esta perspectiva é utilizada nas Quatro Varas no tratamento de pacientes com problemas psicossociais, integrada à TCl. Dado que os hortos também constituem espaço aberto a visitas e socialização, tornase aparente a multifuncionalidade das FVs.

Em vez de se centrarem na produção de plantas medicinais, conforme prescrito pela política estadual, os hortos de Fortaleza se baseiam no cultivo de elevada biodiversidade em combinações espaciais e temporais diversas, não utilizam agrotóxicos e os insumos externos são basicamente mudas, sementes e fertilizantes orgânicos. Assim, constituem agricultura urbana diversificada com baixo nível de insumos externos, favorecendo a sua autonomia. Tal prática sugere a necessidade de mudanças na condução agrícola proposta pela PPPMF do Ceará, pois mais do que o trabalho permanente de agrônomo ou técnico agrícola focado em plantas medicinais, aparentemente o que se requer é uma assessoria continuada na produção de plantas medicinais, consorciadas com hortaliças, ornamentais e frutíferas.

Essa 'cultura' de autonomia das FVs fez com que seja dispensável em maior ou menor grau a aquisição de matéria prima de outras fontes para sua transformação pelas FVs em fitoterápicos e/ou produtos manipulados. Desse modo, sugere à Política maior atenção à produção e transformação de forma integrada nas FVs, reduzindo o peso à separação dos elos da cadeia em produtores, beneficiadores e transformadores.

Dado que parte dos sujeitos é simultaneamente formulador de propostas, gestor, executor e/ou beneficiário, o protagonismo múltiplo é um aspecto relevante na motivação e definição dos objetivos dos mesmos.

\section{CONSIDERAÇÕES FINAIS}

O estudo permitiu caracterizar as FVs de Fortaleza e indica que ao analisar a relação entre a normatização e a prática da PPPMF do Ceará, é preciso considerar não somente a prescrição técnico/normativa, mas as adaptações e inovações promovidas pelos sujeitos em suas práticas sociais e produtivas, pois são estes que melhor podem retroalimentar a política pública.

A dinâmica social e técnica desenvolvida localmente nas FVs apresenta-se ancorada em ação coletiva e solidariedade e toma forma material e simbólica em sistemas integrados de produção, transformação, consumo e dádiva.

Se no início das FVs, o resgate de conhecimento local sobre plantas medicinais e seus usos, enriquecido pela pesquisa científica farmacológica tiveram na difusão de inovações um importante aliado para difundir esses conhecimentos na sociedade, atualmente a PPPMF poderia se beneficiar incorporando diretrizes e metodologias da Política Nacional de Assistência Técnica e Extensão Rural - PNATER (BRASIL, 2004), ao favorecer o diálogo entre os atores sociais e uma abordagem sistêmica.

Assim, uma estratégia para revitalizar as FVs no Estado do Ceará, que incorpore os aspectos acima ressaltados, poderá implicar em: realizar diagnósticos participativos nas FVs; elaborar projetos integrados, visando o manejo sustentável de agroecossistemas diversificados e unidades de beneficiamento e transformação e; disponibilizar recursos para investimentos e troca de conhecimentos entre os diferentes sujeitos. 
A gestão e financiamento de tal estratégia requerem atuação multidisciplinar e intersetorial dos órgãos do governo e da sociedade civil. O estudo demonstra que tanto a UFC, quanto as FVs, vem desenvolvendo experiência e competências pertinentes, as quais podem servir de pontos de alavancagem para a atuação de uma assessoria socioambiental e sistêmica, orientada aos atores sociais.

O estudo realizado em nível municipal proporciona uma base metodológica que pode ser ampliada aos diversos sujeitos das FVs em níveis de agregação socioambiental ascendentes, tais como o estadual e o nacional.

\section{REFERÊNCIAS}

ANVISA. Resolução - RDC № 18, de 3 de abril de 2013. Dispõe sobre as boas práticas de processamento e armazenamento de plantas medicinais, preparação e dispensação de produtos magistrais e oficinais de plantas medicinais e fitoterápicos em farmácias vivas no âmbito do Sistema Único de Saúde (SUS). Agência Nacional de Vigilância Sanitária, 2013.

ANVISA. Farmacopeia brasileira, v.2. Brasília: Agência Nacional de Vigilância Sanitária, 2010.

BANDEIRA, M. A. M. Professor Matos: a transcendência do gênio. Pharmacia Brasileira, 2009. jan/fev. (Entrevista concedida a Aloísio Brandão).

BARDIN, L. Análise de conteúdo. Lisboa: Edições 70, LDA, 2002.

BARROS, M. E. N.; GAMARRA-ROJAS, G.; SOUSA, A. M. O horto do Movimento Mulheres da Itaoca: contribuição para a saúde e desenvolvimento social. 1. ed. Saarbrücken: Novas Edições Acadêmicas, 2017.

BRASIL. Ministério do Desenvolvimento Agrário. Política nacional de assistência técnica e extensão rural. Versão Final. Maio 2004. Disponível em: http://www.mda.gov.br/sitemda/sites/sitemda/files/user_arquivos_64/Pnater.pdf.

Acesso em: 26 jan. 2019

BRAVO, M.I.S. Política de saúde no Brasil. In: MOTA, A.E. et al. (orgs.). Serviço social e saúde, 3. ed. São Paulo: Cortez, 2008.

CEARÁ. Decreto ํㅜ 30.016, de 30 de dezembro de 2009. Regulamenta a lei oㅜ 12.951, de 07 de outubro de 1999. Dispõe sobre a política de implantação da fitoterapia em saúde pública no Estado do Ceará e dá outras providências. Diário Oficial do Estado, 2010; 08 jan.

FLEURY, S.; OUVERNEY, A.M. Política de saúde: uma política social. In: GIOVANELLA, L.; ESCOREL, S.; LOBATO, L.V.C. (orgs). Políticas e sistemas de saúde no Brasil. Rio de Janeiro: FIOCRUZ, 2008.

FONSECA, M.T.L. Extensão rural no Brasil: um projeto educativo para o capital. São Paulo: Loyola, 1985.

FRANÇA, E.; VASCONCELLOS, A.G. Patentes de fitoterápicos no Brasil: uma análise do andamento dos pedidos no período de 1995-2017. Cadernos de Ciência \& Tecnologia, Brasília, v.35, n.3, p.329-359, 2018. 
GAMARRA-ROJAS, G.; SILVA, N. C. G.; VIDAL, M. S. C. Contexto, (agri)cultura e interação no agroecossistema familiar do caju no semiárido brasileiro. Cadernos de Ciência \& Tecnologia, Brasília, v.34, n.3, p.315-338, 2017.

GUZMÁN, E.; OTTMANN, G. Los procesos de modernización y cientificación como forma de agresión a la biodiversidad sociocultural. Cultura, Hombre y Sociedad, Chile. v.5, n.1, p.57-68, 1999-2000.

HEIDEMANN, F. G.; SALM, J. F. (orgs). Políticas públicas e desenvolvimento: bases epistemológicas e modelos de análise. Brasília: Editora Universidade de Brasília; 2008.

HÖFLING, E. M. Estado e políticas (públicas) sociais. Cadernos Ceres, v.21, n.55, p.30-41, 2001.

JATAI, J. M.; SILVA, L. M. S. Enfermagem e a implantação da Terapia Comunitária Integrativa na Estratégia Saúde da Família: relato de experiência. Revista Brasileira de Enfermagem, v.65, n.4, p.691-695, 2012.

MAURO, S. UFC inaugura unidade da Farmácia Viva no Jangurussu. Fortaleza. Agência Funcap, 2009. Maio 14.2 Disponível em: http://www.funcap.ce.gov.br/index.php/noticias/43542--ufc-inaugura-unidade-dafarmacia-viva-no-jangurussu-. Acesso em: 12 dez. 2015.

NEDER, C. R.; PINHEIRO, S. A. Terapia Comunitária em ambulatórios universitários: relato de experiência. Mundo da Saúde, v.34, n.4, p.520-525, 2010. Disponível em: http://www.saocamilo-sp.br/pdf/mundo_saude/79/520.pdf. Acesso em: 30 nov. 2015.

RÊGO, L. Exemplo de sucesso em Terapia Comunitária: Projeto 4 Varas, FortalezaCE. Rede Humaniza SUS, $2014 . \quad$ Disponível em: http://www.redehumanizasus.net/88147-exemplo-de-sucesso-em-terapiacomunitaria-projeto-4-varas-em-fortaleza-ce. Acesso em: 30 nov. 2015.

ROGERS, E. M. Diffusion of innovations. 3 ed. New York: The Free Press, 1983.

RUFINO, L. L. Farmácias Vivas: o contexto do uso de plantas medicinais e fitoterápicos por meio dos atores sociais no município de Fortaleza. 2015. 118f Dissertação (Mestrado Acadêmico em Economia Rural) - Programa de PósGraduação em Economia Rural, Universidade Federal do Ceará.

SECCHI, L. Políticas públicas: conceitos, esquemas de análise, casos práticos. $2^{a}$ ed. São Paulo: Cengage Learning, 2013.

SILVA, M. O. S. Avaliação de políticas e programas sociais: uma reflexão sobre o conteúdo teórico e metodológico da pesquisa avaliativa. In: SILVA, M.O.S. (org.) Pesquisa avaliativa: aspectos teórico-metodológicos. São Paulo: Vera Editora; São Luiz: GAEPP, 2008.

SOUSA, C. Políticas públicas: uma revisão da literatura. Porto Alegre: Sociologias v.8, n.16, p.20-46. 2006. 
TEÓFILO, J. Farmácia Viva de universidade distribui fitoterápicos para postos de saúde de Fortaleza. Tribuna do Ceará, 2015. Out 16. Disponível em: http://tribunadoceara.uol.com.br/noticias/saude/farmacia-viva-de-universidadedistribui-fitoterapicos-para-postos-de-saude-de-fortaleza/\#. Acesso em: 10 dez. 2015. 